\title{
NOISE REDUCTION FOR BALLASTED TRACKS: A SOCIO-ECONOMIC ASSESSMENT
}

\author{
ALEJANDRO ORTEGA ${ }^{1}$, SIMON BLAINEY ${ }^{1}$, JOHN PRESTON ${ }^{1}$, DAVID THOMPSON ${ }^{2}$, \\ GIACOMO SQUICCIARINI ${ }^{2}$, EVANGELOS NTOTSIOS ${ }^{2} \&$ JOHN ARMSTRONG $^{1}$ \\ ${ }^{1}$ Transportation Research Group, University of Southampton, UK \\ ${ }^{2}$ Institution of Sound and Vibration Research, University of Southampton, UK
}

\begin{abstract}
Transport infrastructure produces many externalities. Increased accessibility and the resultant economic development are among the most notable positive ones. Accidents, air and noise pollution, and other environmental issues, such as impacts on biodiversity, landscape and townscape, are the most important negative ones. In the case of railway infrastructure, noise and vibration impacts have a key effect on net social benefit. Noise and vibration reduction is crucial to achieve greater social benefits. In this context, the University of Southampton has been working on the Track to the Future (T2F) project, which is assessing, among other issues, how to produce a quiet ballasted track system that is also cheaper to maintain and renew. This paper considers combinations of engineering interventions that could reduce noise and vibration. These include under sleeper pads which attenuate ground vibration, rail dampers and noise barriers which reduce airborne noise. The effects on noise and vibration of under sleeper pads are determined using detailed engineering models. The overall benefits are then assessed for a notional section of track based on a typical route in the UK.
\end{abstract}

Keywords: comfort, noise, railway, reliability, under sleeper pads, upgrades.

\section{INTRODUCTION}

In the UK, as in several other national contexts, the ability of the current railway infrastructure to accommodate the expected future growth in demand is questionable [1]. Amongst other factors, increasing traffic volumes will place significant pressure on the railway track and sub-base, leading to accelerated deterioration of track components. While this can be mitigated through routine maintenance and renewal activities, these incur costs and can cause significant disruption to services. In order to increase frequencies and to operate faster and heavier trains with less need for maintenance, opportunistic improvements to the railway track should therefore be made [2]. This applies to any developed region where the railway system is under pressure due to the combination of both high demand and ageing infrastructure. Under these circumstances, track system interventions should be made where they have a positive business case. There are various developments in the construction and maintenance of track and sub-base which could deliver improved reliability, reduced travel times and reductions in perceived noise (amongst other benefits) [2]. The economic appraisal of such interventions helps to ensure that their assessment has similar levels of rigour to other transport investments. Cost Benefit Analysis (CBA) to compare the benefits and costs of the project/investment, Input Output Tables to assess the effect of the investment on regional or sectoral economies, and Multi Criteria Analysis to rank different alternatives according to investment preferences are among the most widely used means of undertaking these appraisals. Cost modelling is a vital element of these approaches and has a significant effect on the outputs of the analysis [3], and any errors reduce the accuracy of the calculated return on investment. Although this uncertainty cannot be fully eliminated [4], it is important that all significant costs and benefits are assessed and reflected in these economic analyses with sufficient accuracy [5]. 
One of the most popular track upgrades in Europe is the installation of under sleeper pads (USPs), which are elastic elements usually made of rubber which are fixed beneath the sleepers in ballasted railway track and affect the behaviour of the track. The effect of USPs has been studied from many points of view; their impacts on track quality improvements and on reductions of vibration are particularly well acknowledged [6]. However, there appears to be a gap in the literature regarding the socioeconomic effect of track renewals, causing uncertainty for railway infrastructure managers (IMs) considering upgrades of conventional track. Specifically, the authors only found one example of recent research [7] estimating the social gains (or costs) of installing USPs. This paper's primary objective is therefore to investigate this area and provide useful information for policy makers considering installation of USPs. To do this, and to enable a reliable economic appraisal of such track upgrades, this paper reviews the valuation of some of the most relevant factors associated with such upgrades and applies the findings to a CBA of the installation of USPs during track renewals. Although the review is applied to an analysis of the installation of USPs, it could also be used for other track interventions such as random fibre reinforcements. So, according to Van Wee and Banister [8] this paper mainly adds value for real-world applications: a thorough review is followed by a case study which demonstrates how to use these values for investment appraisal. Following this introduction, the paper has five sections: first, a review of values of noise is described; second, values of vibration and ride quality are set out; third, to connect the literature review with a practical case study, an illustrative example from the UK is provided, which assesses the effects of USP installation in a hypothetical complete renewal on the route between Portsmouth and London. Ongoing and future work is then outlined. Finally, based on this research, the paper provides conclusions for policy makers.

\section{VALUATIONS OF NOISE}

\subsection{Overview}

While changes in noise levels affect both rail users and people living or working adjacent to railway lines, the literature reviewed concentrates overwhelmingly on the latter group, with no valuations provided of the effects of noise on rail passengers. Few papers discuss on-board noise, and those which do tend to be outdated (see, for instance, [9]).

The character of the nuisance associated with railway noise is more similar to that generated by air traffic than to that from road traffic, with greater peaks in noise levels, but negligible background noise. This means that there may be significant differences between the maximum measured noise level and the equivalent level of noise over a particular time period [10]. Railway noise is widely considered to be less disturbing than road noise of an equivalent level, and it may therefore be necessary to account for a railway noise 'bonus' (similar to a reduction of noise) if additional rail services lead to modal shift from road transport. This might be explained by different sources of noise or because people tend to be used to railway noise. On the other hand, De Coensel et al. [11] do not find statistical evidence that railway noise is less of a nuisance than noise from road traffic. This difference can be explained by the fact that people were asked to evaluate this annoyance over a longer period of time than in other studies. The perception of noise follows a logarithmic scale and therefore higher initial levels of noise leads to lower impacts from additional noise [12].

Andersson and Ögren [10] divide the social costs of exposure to noise into three categories, although they note that they are not completely separable: resource costs (i.e. medical and health service costs), opportunity costs (i.e. the cost of lost productivity and the opportunity cost of leisure) and disutility (i.e. other social and economic costs, including 
inconvenience, discomfort, and anxiety and concern about the future). Staatsen et al. [13] point out that the disutility of noise will clearly dominate eventual medical costs, and therefore valuation techniques should focus on the measurement of this utility loss. There may be economic costs resulting from the loss of utility, as it may have a negative impact on property values and restrict construction plans in the vicinity of railways [14]. In addition, noise emission and immission values may well be unequal, since the latter will reflect the distance between the track and the measurement location, variations in weather conditions, and the presence and characteristics of objects situated between the track and the measurement location [14]. The local nature of noise cost estimates and their dependence on background noise levels makes them difficult to generalise [15]. Also, the impact of a given level of noise will depend on people's activities and their attitudes towards the railway, and their annoyance levels may decrease as they become familiar with a given level of noise exposure [14].

In the studies reviewed, three different approaches were taken to the evaluation of noise costs: hedonic pricing (HP), (where the real market is used to determine the economic value of the point of interest), stated preference (SP) surveys (generally conducted to ascertain willingness to pay (WTP) or contingent valuation (CV)), and estimation of the costs of abatement. WTP values can be obtained from HP as well as from SP surveys, but, as Strand and Vagnes [16] point out, there are various problems associated with such a derivation. Valuations of noise nuisance obtained using HP methods tend to be overestimated relative to SP surveys such as Contingent Valuation Method (CVM) or Stated Choice (SC) experiments, and there are also differences between the results obtained from CVM and SC [17].

\subsection{Costs of annoyance per person}

Navrud et al. [18] estimated mean WTP for elimination of rail noise annoyance in UK. Nijland et al. [19] similarly estimated WTP per person per $\mathrm{dB}(\mathrm{A})$ reduction in the Netherlands. They found that below $55 \mathrm{~dB}(\mathrm{~A})$ (commonly assumed to be the lower limit at which people are willing to pay to avoid noise) there were no effects on the housing market and consequently no benefits from noise reduction can be assumed. However, the UK Department for Transport [20] set this threshold at $45 \mathrm{~dB}(\mathrm{~A})$, and Nijland et al. [19] pointed out that people may experience annoyance at exposure to noise as low as $40 \mathrm{~dB}(\mathrm{~A})$, which suggests that consumer behaviour towards noise exposure differs from the effect of noise exposure on human health and well-being. An earlier study (in German) by Weinberger et al. [21] (quoted in [14]) also presented WTP per person values for different levels of noise reduction, although giving the WTP per month rather than the annual WTP.

A similar but distinct measure of noise is used by two studies and considers the abatement costs involved in reducing noise by a particular level. Oertli and Wassmer [22] estimated the cost of using noise barriers in Switzerland to give a $1 \mathrm{~dB}(\mathrm{~A})$ reduction in noise per inhabitant per month, although their estimated bounds were rather imprecise. Two reports quoted by Brons et al. [14] used the same measure, with Weinberger et al. [21] giving the cost per person of abatement costs to comply with a given limit, and Tyssen [23] giving costs per residential unit in the Netherlands, again to comply with a given limit. However, the level of costs given by Tyssen [23] appears to be an order of magnitude larger than that given by Weinberger et al. [21] and Oertli and Wassmer [22]. 


\subsection{Property value depreciation}

Strand and Vagnes [16] calculated an elasticity of property value with respect to distance as part of an investigation into the relationship between residential property prices and proximity to railways, with valuations based on HP methods and surveys of real estate agents to underpin the conclusions from the HP analysis. Similarly, Howarth et al. [24] estimated the effect of railway noise on property values during their application of a damage assessment methodology to various environmental impacts of transport in the Netherlands. A study by van Kempen [25], also from the Netherlands, presented results in the same format, with two sets of depreciation estimates based on HP and CV. A slightly earlier British HP study by Sansom et al. [26], looking at a range of surface transport costs and charges, estimated a Noise Depreciation Sensitivity Index (NDSI), indicating the percentage reduction in property values for a $1 \mathrm{~dB}$ increase in noise levels, although this was only disaggregated into low, medium and high noise levels. Bateman et al. [27] also found reductions in property prices in the city of Birmingham, and again, the decline in valuation depended on the noise level. This study was adjusted by Nellthorp et al. [28] to extend the results to cover the whole UK, although in this case, the results are presented as a WTP per household or person per annum.

A HP model was applied to The Netherlands, with a maximum discount for noise levels above $65 \mathrm{~dB}$ and by contrast a premium to sell houses located in very quiet areas (below 40 $\mathrm{dB})$. Residents in high income areas were annoyed by noise at lower noise levels than other residents [29]. Due to the advantages of the SP approach over HP, Bristow et al. [30] carried out an international meta-analysis of SP studies of nuisance due to transportation noise. Consistent with this current review, the authors also found that people who are more exposed to higher noise levels and consequently more annoyed, have higher values of nuisance as well as higher monetary values for aircraft noise. It is notable that the distribution of values for rail noise is highly positively skewed, with few very high values beyond the 90th percentile and those values therefore have a high level of uncertainty. There are more values closer to the 10th percentile than closer to the 90th percentile. The median is lower than the mean, and there are therefore more values below the mean than values higher than the mean.

\subsection{Marginal cost of additional vehicles}

Andersson and Ögren (2007) [10] aimed to estimate railway noise charges (to be included as part of track access charges) using marginal cost principles, based on the official Swedish monetary noise values from an HP value study, with the marginal effect found to be relatively insensitive to the total level of traffic already present on the railway. Indeed, it has been reported that areas of both high traffic speed and high traffic density report lower marginal noise costs [15], suggesting that an additional train has less impact in such cases than in quieter areas. Ögren et al. [31] found that the social marginal cost varies considerably along the network, which is explained mainly by the differences in population density.

\subsection{Other valuations}

One other method for valuing the impact of noise should be mentioned briefly. Bickel et al. [12] used WTP estimates derived from HP studies of house prices to estimate the costs per train-km for different types of train in the UK, and also calculated a train noise cost of $€ 107$ million in the year 1998.

Several conclusions can be drawn from this review. First, there are several formats in which noise valuation can be shown. Second, there are large variations in the economic 
values given to train noise, and these valuations are partly context-dependent. Third, it may therefore be worth adapting the monetary value of noise to the particular case study. Fourth, the larger the annoyance due to noise, the larger the valuation of it. For example, in the UK context, values of noise can vary between $£ 10$ and over $£ 100$ per $\mathrm{dB}$ reduction per household affected per annum.

\section{VALUES OF VIBRATION, RIDE QUALITY AND COMFORT}

A wide-ranging literature search revealed only a small number of studies assigning financial values to the effects of vibration or ride quality. This may be due to passenger comfort and impressions of service quality being affected by a range of factors [32], including time, country, culture or the physical condition of passengers, and when the subjective total contribution from all aspects is similar, then the optimum level of overall comfort will be achieved [33], regardless of the relative contributions of individual contributory factors.

There has been much research into train vibration, especially in the field of off-train vibrations or ground vibrations (see for instance [34]). There are also many studies which find a relationship between on-train vibration and ride quality, but they do not tend to analyse how passengers evaluate it. Evidence suggests that on-board vibration is not perceived by users to be as significant a problem as noise [18]. In fact, noise can reduce vibration discomfort in a proportional way (i.e. vibration does not influence the perception of noise discomfort, but the opposite is not true and noise can have a 'masking effect' on perceptions of discomfort due to vibration) [35]. Howarth and Griffin [36] produced an equivalence contour to help determine whether reductions in noise or off-train vibration would provide more benefit to residents near railway lines, but gave no actual valuations. Sundström and Shafiquzzaman [37] measured the threshold to be able to comfortably read/work in a train, but again without any economic value. Users are also more sensitive to vertical acceleration than to acceleration in the longitudinal or transverse directions [38]. The concepts of ride quality and comfort are related but distinct, since comfort is also influenced by other factors such as odours, noise, temperature, lighting etc. On the ride quality aspect, Oborne [39] established some thresholds of comfort, but again gave no financial valuations for these thresholds. Comfort can also be improved by reducing the train speed and consequently the level of vibration [40], but because this would increase travel time and therefore also exposure time, the authors questioned whether this trade-off was worthwhile. Indeed, taken to an extreme, the optimum ride quality would be obtained if the train remained stationary, which is clearly not a realistic option.

\section{CASE STUDY: THE LONDON-PORTSMOUTH LINE}

The main railway line between Waterloo station in London and the English south coast city of Portsmouth runs via Woking and Guildford. It was built, like most of Britain's railways, in the 19th century, and includes some of the country's most intensively-used route sections. Most journeys on the route terminate in or start from London, trains operate at relatively high speeds, and the route is heavily used by commuters. This section of the paper presents the analysis of the economic effects of USP installation on the route between Portsmouth and London Waterloo, focusing on the effect of the variables studied in the literature review, i.e. noise and comfort. As indicated above, the valuation of these variables can vary widely and they therefore require adjustment to the circumstances of the case study. Table 1 shows the minimum, central and maximum values proposed for this route. The basis for choosing these values is explained below. Noise valuations have been set at $£ 20$ per $\mathrm{dB}$ reduction, which would imply an average initial noise level in the range of $50 \mathrm{~dB}-60 \mathrm{~dB}$, which is consistent with the noise maps for the line between Portsmouth and London. In order to avoid double- 
counting, these valuations are kept constant since variations in the levels of ground-borne noise and air-borne noise will themselves generate a range of values for noise-related impacts.

The effects of USP installation can be sub-divided into their installation cost, track maintenance and renewal requirements, rolling stock, noise and ride quality/comfort. Table 2 summarises the anticipated effects, and whether they are considered to be positive, neutral or negative in terms of the CBA. Indirect effects such as avoided road congestion have not been included in the analysis.

According to Abadi et al. [41] the Local Track Sector Modifier (LTSF) - which is essentially a lumped factor to account for variation of local track from the idealised deterioration rate - would be reduced by $25 \%$ as a result of the installation of stiff, $4 \mathrm{~mm}$ thick USPs, and the primary benefit would result from increased track service life and reduced maintenance requirements [42], whilst maintaining railway track geometry at adequate standards [43]. In the course of an interview with Network Rail it was noted that USPs tend to degrade more quickly than other track components: the maintenance and renewals savings were therefore reduced by one third.

Table 1: Values to be used in the economic appraisal.

\begin{tabular}{|l|c|c|c|c|}
\hline Variable & Measure & Minimum value & Central & Maximum \\
\hline $\begin{array}{l}\text { Air-borne } \\
\text { noise }\end{array}$ & $\begin{array}{c}\text { dB increase of } \\
\text { households affected }\end{array}$ & $0 \mathrm{~dB}$ & $1 \mathrm{~dB}$ & $2 \mathrm{~dB}$ \\
\hline $\begin{array}{l}\text { Ground-borne } \\
\text { noise }\end{array}$ & $\begin{array}{c}\mathrm{dB} \text { reduction of } \\
\text { households affected }\end{array}$ & $4 \mathrm{~dB}$ & $5 \mathrm{~dB}$ & $6 \mathrm{~dB}$ \\
\hline Noise value & $\begin{array}{c}£ \text { per dB per } \\
\text { household affected }\end{array}$ & - & $£ 20$ & - \\
\hline $\begin{array}{l}\text { Ride Quality/ } \\
\text { Comfort }\end{array}$ & $\begin{array}{c}\text { Value per passenger } \\
(\% \text { of ticket price })\end{array}$ & $0 \%$ & $1 \%$ & $2 \%$ \\
\hline
\end{tabular}

Table 2: Anticipated effects on CBA assessment.

\begin{tabular}{|l|l|l|}
\hline Effect considered & $\begin{array}{l}\text { Evolution of } \\
\text { the variable }\end{array}$ & Effect on the CBA \\
\hline Installation cost of USPs & Increase & Negative \\
\hline Maintenance and renewal needs & Decrease & Positive \\
\hline Rolling Stock & No change & Neutral \\
\hline Air - borne noise & Increase & Negative \\
\hline Ground - borne noise & Decrease & Positive \\
\hline Ride Quality/Comfort & Increase & Positive \\
\hline Improved travel time & No change & Neutral \\
\hline Induced demand & No change & Neutral (not considered) \\
\hline Road congestion & Decrease & Neutral (not considered) \\
\hline
\end{tabular}


The cost values used are generated by the Vehicle Track Interaction Strategic Model (VTISM), a computer model developed and used in Britain to assess the effects of different infrastructure, rolling stock and asset management policies on track life and infrastructure costs. Approximately 400,000 USPs would be installed on the route, with an expected unit cost of $£ 15$ (2009 prices). With the expected investment and track maintenance and renewal, the financial implications for Network Rail (the IM) are known. Based on the VTISM results, while maintenance requirements in the form of tamping are reduced as a result of the installation of USPs, rail renewal requirements would increase by approximately $10 \%$ over the 60 -year period. No evidence was found that increased rail renewals would cause rolling stock deterioration, and this was therefore excluded from the analysis. Noise for non-users was split between air-borne noise and ground-borne noise, since USP installation could result in a slight increase of air-borne noise [44], but a more significant decrease in ground-borne noise [45]. The value chosen for noise is $£ 20$ per house and year whilst the ranges for maximum and minimum noise increases/decreases follow the values of these studies. USP installation would also result in reduced noise inside trains, and improved ride quality due to the reduction of vertical acceleration [46], but would not affect other attributes of comfort, so a conservative range of $0 \%$ to $2 \%$ of the fare was used. The methodology used to calculate these impacts is described in detail in [7] and is based upon a stochastic approach supported by sensitivity analysis, running multiple Monte Carlo simulations within a spreadsheet-based model. For the calculations, the analysis was restricted to passengers using the major stations on the route with a journey time of at least 30 minutes to/from Waterloo (i.e. Portsmouth Harbour, Portsmouth and Southsea, Fratton, Havant, Petersfield, Haslemere, Guildford and Woking). The length of the route under consideration is approximately 74 miles $(119 \mathrm{~km})$, the assumed project life for the analysis is 60 years, the initial year is 2009 and the chosen discount rate is $3.5 \%$. The remaining economic parameters, including demand and demand growth, were obtained from the WebTAG [20] and National Rail Trends (NRT) websites. The results of the spreadsheet-based Cost Benefit Analysis carried out are shown in Table 3. Three main conclusions are drawn from these results. First, and notably, all stakeholders benefit from the intervention: train operating companies (TOCs) due to an indirect effect of potential revenue growth with increased rail demand generated by improved comfort; the IM would obtain a net financial benefit as a result of investment costs for USPs and benefits linked to lower maintenance; travellers would have a better journey experience in terms of comfort/ride quality; and non-users would avoid some train noise. The only exception to this rule is the category of non-users living within 80 to 300 metres from the track, who may be

Table 3: Present value (2009 prices) for each stakeholder and impact.

\begin{tabular}{|l|c|c|c|c|}
\hline Variable & $\begin{array}{c}\text { Stakeholder } \\
\text { affected }\end{array}$ & $\begin{array}{c}\text { Most } \\
\text { pessimistic } \\
\text { (£million) }\end{array}$ & $\begin{array}{c}\text { Central } \\
\text { (£million) }\end{array}$ & $\begin{array}{c}\text { Most } \\
\text { optimistic } \\
\text { (£million) }\end{array}$ \\
\hline Air-borne noise & Non-users & -129.94 & -64.97 & 0 \\
\hline $\begin{array}{l}\text { Ground-borne } \\
\text { noise }\end{array}$ & Non-users & 101.77 & 127.21 & 152.65 \\
\hline $\begin{array}{l}\text { Ride quality/ } \\
\text { comfort }\end{array}$ & $\begin{array}{c}\text { Rail users and } \\
\text { TOCs }\end{array}$ & 0 & 102.82 & 205.65 \\
\hline Financial benefit & Network Rail & 29.88 & 29.88 & 29.88 \\
\hline TOTAL & & 1.71 & 194.94 & 388.18 \\
\hline
\end{tabular}


negatively affected by increased air-borne noise, although at that distance air-borne railway noise is unlikely to be the dominant noise source. Non-users living within $80 \mathrm{~m}$ of the track are affected by ground-borne noise [47] and therefore would benefit from its reduction. More houses along the route are affected by air-borne than by ground-borne noise $(78,000 \mathrm{vs}$ 30,500 ), so the greater benefit for the latter is explained by ground-borne noise reduction. The net financial benefit to Network Rail as IM is almost $£ 30$ million. As expected, VTISM indicates fewer interventions due to maintenance requirements in the track than without USPs. This would mean fewer replacement bus services during engineering possessions, thus reducing costs, and congestion could also be reduced for road users, another indirect benefit not explicitly considered for the purposes of this analysis.

The second conclusion also concerns the fairness of this investment, since the stakeholder making the investment would enjoy only a minority of the resulting benefits. In this case, Network Rail would make the hypothetical investment and would receive a net benefit, taking into account investment costs for USPs and benefits linked to lower maintenance. However, users would perceive an improved travel experience due to the gains in ride quality, at no extra cost. The same applies to TOCs, who would save money based on the reduced need to operate replacement buses during engineering works. Similarly, property owners would gain from the increased valuation of their properties as a result of reduced noise after the installation of USPs. Even though the ratio of net benefit/investment is high (5:1) for the IM, it would thus only accrue about $10 \%$ of the final benefits.

The final conclusion is related to the high levels of uncertainty and variability of the results, since the highest Net Present Value (NPV) is much greater than the lowest. For each single $\mathrm{dB}$ increase in air-borne noise, the NPV is reduced by almost $£ 65$ million. Groundborne noise is also very significant, since each $\mathrm{dB}$ reduction increases the NPV by $£ 26$ million. If a track intervention improves Ride Quality/Comfort to an extent equivalent to just $1 \%$ of the ticket price, it produces a social gain of $£ 102$ million in NPV. This type of intervention is completely within the control of TOCs and the IM, and there is thus scope for realistic, achievable and widely beneficial track upgrades. Britain's railways are among Europe's oldest, and in order to achieve better performance of the railway system for society as a whole, it is important to avoid welfare losses from users with high valuations of their trips or from the externalities arising from those trips. So, for this particular case study, it is worth upgrading the infrastructure to 21 st century standards.

\section{ONGOING AND FUTURE WORK}

Investigation and assessment of alternative noise reduction measures to USPs is also underway. Such measures range from the sound insulation of affected buildings and the provision of trackside noise barriers, to alternative track-based measures like rail dampers, and vehicle-based measures like brake shoe modifications [48]. The sound insulation of adjacent buildings is quite situation-specific and beyond the scope of the current project, the focus of whose ongoing work is upon track-based measures. Even low noise barriers have been found to be effective in reducing noise adjacent to and above the track [49], and, in cases where barriers are unacceptable, rail dampers have been found to be an effective alternative [50]. Work is ongoing to model and assess the costs and benefits of noise barrier and rail damper installation, and it is anticipated that initial results will be available for presentation at COMPRAIL 2018.

\section{CONCLUSIONS}

Before conducting any transport investment, it is sensible to forecast and quantify its overall consequences through an appraisal such as a CBA. CBA is normally used to appraise new 
transport infrastructure, but it can also be used for current activities like maintenance and renewals. When rail maintenance and renewal activities are undertaken, a comprehensive analysis should include the effects of subsequent noise and vibration levels on both railway users and non-users, and changes to ride quality and their impacts on passengers and other railway industry stakeholders. In this paper, a review has been undertaken of the evidence relating to valuations of these factors, with the aim of producing a meta-analysis of those valuations. The coverage of the evidence base has a high degree of variability, with little research having been undertaken on the monetary values of vibration, ride quality and comfort for rail users. In contrast, noise has been extensively studied in the academic literature.

The high level of variability has several causes: first, differences were found between regions, traveller types and affected non-travellers; second, the values used in the analysis vary with the chosen approach, as in the case of ride quality, which can be valued in relation to in-vehicle time or as a percentage of the ticket price; and, finally, HP methods and SP surveys usually produce different outcomes and values, whilst bias can also be found in some results. More recently, transportation noise valuations have been based upon epidemiological studies that estimate damage costs in terms of the impact on public health [51], [52].

The review and results emphasise the need to undertake a twofold evaluation of the effects of noise: first, of its external effects on non-railway users living or working close to a railway line; and, second, as a factor affecting railway passenger comfort. For example, the erection of noise barriers beside a railway line will reduce the external effects of train-generated noise, but train travellers will continue to be affected (and possibly more so, due to reflection) by noise, while also losing the potential benefits of an unobstructed view from the train. Despite recent improvements to the valuation of ride quality and passenger comfort, the available values lack consistency, and further research is required in this area.

For the purposes of conducting an economic appraisal and producing robust, genuinely representative results, the work and case study described in this paper demonstrate the importance of using economic valuations appropriate to the situation under consideration, and the value of using sensitivity tests to identify the most important parameters and provide clear guidance for policy makers. They also show that a relatively modest, readily achievable modification of existing railway infrastructure can generate significant benefits for multiple stakeholders, although most of the benefits may not be enjoyed by the organisation making the investment. This is particularly relevant to developed countries with long-established and heavily-used railway infrastructure, like the UK, where the construction of new routes is in many cases less feasible or attractive than cost-effective upgrades of the existing system.

\section{ACKNOWLEDGEMENTS}

The research described has been conducted by the authors as part of the EPSRC-funded TRACK21 (EP/H044949/1) and Track to the Future (EP/M025276/1) projects. The laboratory test results, and other parameters such as USP costs, have been provided by other researchers working on the project. The named authors are solely responsible for the review of the test results and for the conclusions presented. The data used in the research have been deposited in the University of Southampton library: https://doi.org/10.5258/SOTON/D0129.

\section{REFERENCES}

[1] Frost, M.W., Ison, S.G. \& Watson, R., UK rail transport: a review of demand and supply. Proceedings of the ICE - Transport, 165(3), pp. 225-234, 2012.

[2] Powrie, W., On track: the future for rail infrastructure systems. Proceedings of the Institution of Civil Engineers - Civil Engineering, 167(4), pp. 177-185, 2014. 
[3] Ortega, A., Vassallo, J., Guzmán, A. \& Pérez-Martínez, P., Are Longer and Heavier Vehicles (LHVs) beneficial for society? A cost benefit analysis to evaluate their potential implementation in Spain. Transport Reviews: A Transnational Transdisciplinary Journal, 34(2), pp. 150-168, 2014.

[4] Salling, K. \& Nielsen, O., Uncertainties in transport project evaluation: editorial. European Journal of Transport and Infrastructure Research, 15(3), pp. 282-285, 2015.

[5] Asplund, D. \& Eliasson, J., Does uncertainty make cost-benefit analyses pointless? Transportation Research Part A: Policy and Practice, 92, pp. 195-205, 2016.

[6] Schilder, R., USP (Under Sleeper Pads): a contribution to save money in track maintenance. AusRAIL PLUS, driving the costs out of rail, 2013.

[7] Ortega, A., Blainey, S. \& Preston, J., Installation of under sleeper pads on ballasted railway track: an economic analysis of their potential implementation. Proceedings of the Institution of Mechanical Engineers, Part F: Journal of Rail and Rapid Transit, 2017.

[8] Van Wee, B. \& Banister, D., How to write a literature review paper? Transport Reviews, 36(2), pp. 278-288, 2016.

[9] Eade, P. \& Hardy, A., Railway vehicle internal noise. Journal of Sound and Vibration, 51(3), pp. 403-415, 1977.

[10] Andersson, A. \& Ögren, M., Noise charges in railway infrastructure: A pricing schedule based on the marginal cost principle. Transport Policy, 14, pp. 204-213, 2007.

[11] De Coensel, B., Botteldooren, D., Berglund, B., Nilsson, M.E., De Muer, T. \& Lercher, P., Experimental investigation of noise annoyance caused by high-speed trains. Acta Acustica United with Acustica, 93(4), pp. 589-601, 2007.

[12] Bickel, P., Friedrich, R., Link, H., Stewart, L. \& Nash, C., Introducing environmental externalities into transport pricing: measurement and implications. Transport Reviews: A Transnational Transdisciplinary Journal, 26(4), pp. 389-415, 2006.

[13] Staatsen, B., Nijland, H.A., van Kempem, E.M.M., de Hollander, A.E.M., Franssen, A.E.M. \& van Kamp, I., Assessment of health impacts and policy options in relation to transport-related noise exposures. RIVM Report, 2004.

[14] Brons, M., Nijkamp, P., Pels, E. \& Rietveld, P., Railroad noise: economic valuation and policy. Transportation Research D, 8, pp. 169-184, 2003.

[15] Nash, C., Unification of Accounts and Marginal Costs for Transport Efficiency: Final Report, ITS, University of Leeds, Online. http://www.its.leeds.ac.uk/projects/unite/ downloads/Unite\%20Final\%20Report.pdf. Accessed on: 19 Mar. 2018.

[16] Strand, J. \& Vagnes, M., The relationship between property values and railroad proximity: a study based on hedonic prices and real estate brokers' appraisals. Transportation, 28, pp. 137-156, 2001.

[17] Bristow, A., Wardman, M. \& Chintakayala, V., International meta-analysis of stated preference studies of transportation noise nuisance. Transportation, 42, pp. 71-100, 2015.

[18] Navrud, S. et al., Economic values for key impacts valued in the Stated Preference surveys, Developing Harmonised European Approaches for Transport Costing and Project Assessment (HEATCO), Online. http://heatco.ier.unistuttgart.de/HEATCO_D4.pdf. Accessed on: 19 Mar. 2018.

[19] Nijland, H., van Kempen, E., van Wee, G. \& Jabben, J., Costs and benefits of noise abatement measures. Transport Policy, 10, pp. 131-140, 2003. 
[20] WebTAG: TAG data book, December 2017, Department for Transport, Online. https://www.gov.uk/government/publications/webtag-tag-data-book-december-2017. Accessed on: 19 Mar. 2018.

[21] Weinberger, M., Thomassen, H. \& Willeke, R., Kosten des Larms in der Bundesrepublik Deutschland, Erich Schmidt Verlag: Berlin, 1991.

[22] Oertli, J. \& Wassmer, D., Rail noise control in Switzerland: legislation, environment, politics and finances. Journal of Sound and Vibration, 193, pp. 403-406, 1996.

[23] Tyssen, L., Consequenties van Voorgenomen Woningbouwplannen van het Aanhouden van Grenswaarden met betrekking tot Spoorweglawaai. Transportation 28, pp. 137-156, 1982.

[24] Howarth, A. et al., Valuing the benefits of environmental policy: The Netherlands, RIVM Report, 2001.

[25] van Kempen, E., Een schatting van de baten van geluidmaatregelen. The Netherlands, RIVM Report, 2001.

[26] Sansom, T., Nash, C., Mackie, P., Shires, J. \& Watkiss, P., Surface Transport Costs and Charges Great Britain 1998, Institute for Transport Studies, University of Leeds, Online. http://www.its.leeds.ac.uk/fileadmin/user_upload/Surface_Transport_Costs and_Charges_Great_Britain_2001.pdf. Accessed on: 19 Mar. 2018.

[27] The Valuation of Transport-Related Noise in Birmingham, University of East Anglia, Online. http://webarchive.nationalarchives.gov.uk/20060715203622/http:/www.dft. gov.uk/stellent/groups/dft_econappr/documents/page/dft_econappr_032868.pdf. Accessed on: 19 Mar. 2018.

[28] Nellthorp, J., Bristow, A.L. \& Day, B., Introducing willingness-to-pay for noise changes into transport appraisal: an application of benefit transfer. Transport Reviews: A Transnational Transdisciplinary Journal, 27(3), pp. 327-353, 2007.

[29] Theebe, M.A., Planes, trains and automobiles: The impact of traffic noise on house prices. Journal of Real State, Finance and Economics, 28(2)-(3), pp. 209-234, 2004.

[30] Bristow, A., Wardman, M. \& Chintakayala, V., International meta-analysis of stated preference studies of transportation noise nuisance. Transportation, 42, pp. 71-100, 2015.

[31] Ögren, M., Swärdh, J.-E., Andersson, H. \& Jonsson, L., Noise charges for Swedish railways based on marginal cost calculations, 2011, Online. https://www.divaportal.org/smash/get/diva2:674191/FULLTEXT01.pdf. Accessed on: 19 Mar. 2018.

[32] Grujičić, D., Ivanović, I., Jović, J. \& Đorić, V., Customer perception of service quality in public. Transport, 29(3), pp. 285-295, 2014.

[33] Hardy, A., Measumerent and assessment of noise within passengers trains. Journal of Sound and Vibration, 31(3), pp. 819-829, 2000.

[34] Kouroussis, G., Connolly, D. \& Verlinden, O., Railway-induced ground vibrations - a review of vehicle effects. International Journal of Rail Transportation, 2(2), pp. 69110, 2014.

[35] Huang, Y. \& Griffin, M., The discomfort produced by noise and whole-body vertical vibration presented separately and in combination. Ergonomics, 57(11), pp. 17241738, 2014.

[36] Howarth, H.V.C. \& Griffin, M.J., The relative importance of noise and vibration from railways. Applied Ergonomics, 21(2), pp. 129-134, 1990.

[37] Sundström, J. \& Shafiquzzaman, K., Influence of stationary lateral vibrations on train passengers' difficulty to read and write. Applied Ergonomics, 39(6), pp. 710-718, 2008. 
[38] Castellanos, J.C. \& Fruett, F., Embedded system to evaluate the passenger comfort in public transportation based on dynamical vehicle behavior with user's feedback. Measurement, 47, pp. 442-451, 2014.

[39] Oborne, D.J., Vibration and passenger comfort: Can data from subjects be used to predict passenger comfort? Applied Ergonomics, 9(3), pp. 155-161, 1978.

[40] Karakasis, K., Skarlatos, D. \& Zakinthinos, T., A factorial analysis for the determination of an optimal train speed with a desired ride comfort. Applied Acoustics, 66, pp. 1121-1134, 2005.

[41] Abadi, T., Le Pen, L., Zervos, A. \& Powrie, W., Improving the performance of railway tracks through ballast interventions. Proceedings of the Institution of Mechanical Engineers, Part F: Journal of Rail and Rapid Transit, 2016.

[42] Marschnig, S., Lowering track lifecycle costs with sleeper pads. EURAILmag Business \& Technology, The magazine for European Rail decision makers, 23, pp. 146-147, 2011.

[43] Sol-Sanchez, M., Pirozzolo, L., Moreno-Navarro, F. \& Rubio-Gamez, C., Reducing railway maintenance: the effectiveness of combining the stoneblowing technique with rubber elements from waste tires. Transportation Research Board 95th Annual Meeting, 2016.

[44] Triepaischajonsak, N., The Effect of Sleeper Soffit Pads on Railway Noise, MSc Dissertation, University of Southampton, 2008.

[45] State of the art review of mitigation measures on track. Deliverable D 3.1, UIC, Online. http://www.rivas-project.eu/fileadmin/documents/rivas_uic_wp3_d3_1_v013 final.pdf. Accessed on: 19 Mar. 2018.

[46] Lakušic, S., Ahac, M. \& Haladin, I., Experimental investigation of railway track with under sleeper pad. Proceedings of the Slovenian Congress on the Roads and Traffic, 2010.

[47] Ground-Borne Noise and Vibration in Buildings Caused by Rail Transit, TCRP, Online. http://www.trb.org/Publications/Blurbs/163649.aspx. Accessed on: 19 Mar. 2018.

[48] Real cost of railway noise mitigation; UIC, Online. https://uic.org/IMG/pdf/ba7041101-100-md-af20130168-lok_final_report_uic_real_costs_30jan13.pdf. Accessed on: 19 Mar. 2018.

[49] Ogata, Y. \& Nagakura, K., Noise reduction effect of low barriers installed adjacent to rails. Quarterly Report of Railway Technical Research Institute, 53(3), pp. 173-179, 2012.

[50] Stangl, M., Starnberg, M. \& Asmussen, B., The acoustic qualification process of rail dampers in the German railway network. Proceedings of the $11^{\text {th }}$ World Congress on Railway Research, 2016.

[51] Burden of disease from environmental noise: quantification of healthy life years lost in Europe, WHO. Online, http://www.euro.who.int/_data/assets/pdf_file/0008/ 136466/e94888.pdf. Accessed on: 19 Mar. 2018.

[52] Environmental Noise: Valuing impacts on: sleep disturbance, annoyance, hypertension, productivity and quiet. DEFRA, Online. https://www.gov.uk/ government/uploads/system/uploads/attachment_data/file/380852/environmentalnoise-valuing-imapcts-PB14227.pdf. Accessed on: 19 Mar. 2018. 